\title{
Polypharmacy: droxidopa to treat neurogenic orthostatic hypotension in a patient with Parkinson disease and type 2 diabetes mellitus
}

\author{
Steven Vernino ${ }^{1} \cdot$ Daniel Claassen $^{2}$
}

Received: 7 June 2017 / Accepted: 8 June 2017/Published online: 3 July 2017

(c) The Author(s) 2017. This article is an open access publication

Keywords Type 2 diabetes mellitus - Parkinson disease . Neurogenic orthostatic hypotension · Droxidopa

\section{Challenge question}

In patients with polypharmacy, what medications may limit the potential use of droxidopa?

\section{Case presentation}

Mrs. $\mathrm{K}$ is a 78-year-old woman with Parkinson disease (PD) for which she is receiving carbidopa/levodopa 25/100 mg three times daily (TID). She also has a history of depression for which she takes duloxetine $30 \mathrm{mg}$ twice daily (BID), type 2 diabetes mellitus for which she takes metformin $500 \mathrm{mg}$ TID, and hypertension for which she takes enalapril $5 \mathrm{mg}$ BID.

Recently, she has been experiencing dizziness and lightheadedness along with occasional falls. During a visit to her neurologist, her blood pressure (BP) in the supine position was $138 / 70 \mathrm{mmHg}$, and it dropped to $95 / 60 \mathrm{mmHg}$ in the standing position, with no significant increase in heart rate (HR) upon standing. The patient was thus diagnosed with neurogenic orthostatic hypotension $(\mathrm{nOH})$. Her neurologist considered starting droxidopa,

Steven Vernino

steven.vernino@utsouthwestern.edu

1 Department of Neurology and Neurotherapeutics, UT Southwestern, Dallas, TX, USA

2 Department of Neurology, University of Southern California, Los Angeles, CA, USA although he was concerned because droxidopa should be used with caution in patients who are taking norepinephrine transporter (NET) receptor-blocking medications. These are commonly used for the treatment of depression in PD, and include atomoxetine, duloxetine, bupropion, or venlafaxine. As droxidopa increases plasma norepinephrine, the combination of these two medications could have synergistic effects on this patient's BP. Previous work has shown this synergistic effect with atomoxetine (a NET receptor blocker) and yohimbine (an alpha-2 adrenergic antagonist), which resulted in increased BP [3].

In this case, her neurologist decided that droxidopa was the best medication to treat her symptomatic nOH. To avoid potential synergistic problems between duloxetine and droxidopa, her neurologist transitioned the patient from duloxetine to sertraline, a pure serotonin reuptake inhibitor. Alternatively, the patient could have been prescribed a lower dose of droxidopa and to have been closely monitored. Her neurologist also considered the possibility of using midodrine instead of droxidopa to avoid potential interactions with the NET receptor-blocking medication [4]. Midodrine should be administered with caution in patients with hepatic dysfunction, and it is contraindicated in acute renal failure, urinary retention, pheochromocytoma, and thyrotoxicosis [2]. None of these conditions were present in this patient.

\section{Expert commentary (Dr. Vernino)}

Many patients with $\mathrm{PD}$ and $\mathrm{nOH}$ also have significant supine hypertension $[1,5]$. Additionally, many patients with autonomic failure also have "reverse dipping," a situation where the BP increases during the night and drops in the morning (unlike the normal circadian pattern of BP). 
If sleeping with the head of the bed elevated $30-45^{\circ}$ is not sufficient to alleviate supine nocturnal hypertension, the use of a short-acting antihypertensive medication such as an angiotensin-converting enzyme (ACE) inhibitor, angiotensin receptor blocker (ARB), or topical nitrate at bedtime might be considered.

\section{Expert commentary (Dr. Claassen)}

For a patient such as Mrs. K, my clinical preference would be to evaluate the role and efficacy of the NET medication, change to a selective serotonin reuptake inhibitor, and then titrate with droxidopa. Furthermore, the patient is taking enalapril, an ACE inhibitor, for BP control. This medication can be administered at bedtime, which, in addition to sleeping with the head of the bed elevated $30-45^{\circ}$, can help to reduce supine hypertension.

\section{Case continuation}

To treat this patient's symptomatic $\mathrm{nOH}$, she was started on $100 \mathrm{mg}$ droxidopa on a modified TID schedule (taken before arising from bed in the morning, at midday, and at least 3-4 h prior to bedtime) and uptitrated by $100 \mathrm{mg}$ TID every 24-48 h until $\mathrm{nOH}$ symptomatic relief or the maximum dose of $600 \mathrm{mg}$ TID was achieved. In addition, to avoid synergistic effects on BP, the patient was switched from duloxetine to sertraline (a pure serotonin reuptake inhibitor) $50 \mathrm{mg}$ taken orally once daily (QD). The patient also was instructed to reduce the dosage of enalapril to $5 \mathrm{mg}$ QD at bedtime.

After achieving a steady dose of droxidopa at $600 \mathrm{mg}$ on the modified TID schedule, Mrs. K reported that she was experiencing significantly fewer occurrences of dizziness and had not experienced any falls for the past 2 months. One hour after taking her noon dose of droxidopa, her BP was $135 / 80 \mathrm{mmHg}$ while seated and 99/65 $\mathrm{mmHg}$ upon standing for $3 \mathrm{~min}$.

\section{Expert commentary (Dr. Vernino)}

This patient achieved a good clinical response with the maximum recommended dose of droxidopa, $600 \mathrm{mg}$, TID. In patients with neurodegenerative disorders associated with nOH (like PD), droxidopa must be titrated up to the maximum recommended dose or until the occurrence of side effects before considering the patient's response to be treatment failure. Also, because the metabolism of droxidopa depends on dopa decarboxylase, changes in the dose of carbidopa may require adjustment of the dose of droxidopa. For example, if carbidopa/levodopa were to be discontinued, the physician should monitor for supine hypertension and consider reducing the dose of droxidopa.

\section{Compliance with ethical standards}

Funding source This manuscript is part of a supplement sponsored by Lundbeck.

Conflict of interest Dr. Vernino has served as a consultant for Athena Diagnostics, and on advisory boards and speaker bureaus for Lundbeck.

Dr. Claassen has received research grants from NIH/NINDS, Michael J. Fox Foundation, Vaccinex, CHDI, C2 N, and Auspex, and he is a consultant for Teva Neuroscience, Lundbeck, Acadia, and AbbVie.

Open Access This article is distributed under the terms of the Creative Commons Attribution 4.0 International License (http://crea tivecommons.org/licenses/by/4.0/), which permits unrestricted use, distribution, and reproduction in any medium, provided you give appropriate credit to the original author(s) and the source, provide a link to the Creative Commons license, and indicate if changes were made.

\section{References}

1. Fanciulli A, Gobel G, Ndayisaba JP, Granata R, Duerr S, Strano S, Colosimo C, Poewe W, Pontieri FE, Wenning GK (2016) Supine hypertension in Parkinson's disease and multiple system atrophy. Clin Auton Res 26:97-105

2. McClellan KJ, Wiseman LR, Wilde MI (1998) Midodrine. A review of its therapeutic use in the management of orthostatic hypotension. Drugs Aging 12:76-86

3. Okamoto LE, Shibao C, Gamboa A, Choi L, Diedrich A, Raj SR, Black BK, Robertson D, Biaggioni I (2012) Synergistic effect of norepinephrine transporter blockade and alpha-2 antagonism on blood pressure in autonomic failure. Hypertension 59:650-656

4. Smith W, Wan H, Much D, Robinson AG, Martin P (2016) Clinical benefit of midodrine hydrochloride in symptomatic orthostatic hypotension: a phase 4, double-blind, placebo-controlled, randomized, tilt-table study. Clin Auton Res 26:269-277

5. Umehara T, Matsuno H, Toyoda C, Oka H (2016) Clinical characteristics of supine hypertension in de novo Parkinson disease. Clin Auton Res 26:15-21 